\title{
On the Task-based Language Teaching Method in the English Classroom
}

\author{
Zhen Zhou \\ Foreign Languages College, Nanchang Normal University, Nanchang, Jiangxi, 330032 \\ zoye100@sina.com
}

Keywords: Task-Based language teaching method; Task; Communicative; Preparation; Arrangement; Implementation

\begin{abstract}
The task-based language teaching method is the further development of the communicative language teaching method (CLT) and has become the focus in the foreign language teaching field. TBLT attaches great importance to creating a natural language study environment, providing communicative opportunities and meaning negotiation, facilitaing students' active cognitive participation, and developing competence of using language to do things and solve problems. The article introduces the definition, type, components and application of TBLT in the English classroom, and it aims at improving the quality of English teaching at all levels.
\end{abstract}

\section{Introduction}

The task-based language teaching method refers to an approach based on the use of tasks as the core unit of planning and instruction in the language teaching and is a logical development of communicative language teaching method. TBLT uses specific tasks as learning motivation, uses the process of completing tasks as the process of study, and uses the pattern of showing task results to reflect the achievement of the teaching. TBLT is a classroom teaching method that changes the basic concept of language application to specific practice.

\section{The Definition of the Task}

Different scholars give different definitions of the "task". Long defines the task as "a piece of work undertaken for oneself or for others, freely or for some reward. Thus examples of tasks include painting a fence, dressing a child ...In other words, by "task" is meant the hundred and one thing one does in everyday life, at work, at play and in between. Long thinks that a task is the goal that the students need to achieve in the process of studying English, so we should use the same amount of time in the English classroom. TBLT highlights that students are the main body of the study, and advocates "meaning is the priority, and use is the priority as well". It requires teachers to facilitate the students to learn language through completing the specific task activity, let the students carry out specific language behavior to achieve specific learning goals, and enable students to gain and accumulate learning experience through finishing specific communicative tasks.

\section{The Type of the Task}

Willis comes up with six types of the tasks :

Listing. Listing can produce a great amount of language use, such as, brainstorming, finding out the fact. This kind of task can proceed in the whole class, or in groups or in pairs.

Ordering, Sorting and Classifying. This kind of task requires students to sequence according to the time or logical relation, order according to some standards, classify according to the types. And this process needs students to have a very strong analyzing, concluding and comprehending ability.

Comparing, Matching. Students compare the similar things and find out the similarity and difference.

Problem Solving. This kind of task needs students to use English to solve possible problems that may occur in real life according to their knowledge and reasoning ability. But the key is not the only 
answer, and it is a kind of open type task and creative task. It always gives people satisfaction after they complete the task.

Sharing Personal Experience. This is a frequently-used task in people's daily life in which learners discuss and exchange opinions in the topic and they need not reach an agreement. This kind of tasks can encourage students to use their learned language to tell personal experience, which belongs to a kind of open task.

Creative Tasks. It often appears as the pattern of projects, including a lot of subtasks, in which students experience "condition $\rightarrow$ input $\rightarrow$ process experience $\rightarrow$ output" exploration pattern.

In conclusion, the classification of the task is various, because you can design the task from different angles and different goals, the tasks have their emphasis, but the core is to combine language study, language use with students' comprehensive qualities to carry out teaching.

\section{The Components of TBLT}

Nunan proposes the framework of the communicative language task in the task design in the communicative classroom. The framework includes five components of the structure: goal, input, activity, teacher's role and students' role and environment.

Goal. Goal indicates the target that makes students want to get after finishing the task. The goal of TBLT is to develop students' language communicative competence, this not only indicate the ability to use correct grammar to speak and write, but also includes social language ability, utterance ability and strategy ability, and the understanding ability of language culture.

Input. Input indicates that "material of task design". The input material could be the wordage material, such as the textbooks or dialogues, and could be non-word materials (pictures). The pattern of the input can be various, such as newspapers, novels, movies, advertisements, texts, students' works, poems, and songs. But the output materials should be authentic and interesting, and close to students' life .

Activity. Activity indicates different kinds of activities according to the input material. Therefore, the activities have three characteristics: a. drill of the social life, and reflecting the authenticity and interactivity; b. aiming at the language acquisition and practice; c. emphasizing communicative language's fluency, variety, and appropriateness.

Teacher's/Students' Role. The teacher is the organizer of the study and the organizer of the task in activity, provider of the learning direction and resource, fugleman of the utterance behavior and language behavior, supervisor of the task complete, and sometimes they could join in the activity to act as the partner of the students, at last they act the role of assessor of the feedback of the students.

Environment. Environment indicates the classroom teaching organizing pattern, the pattern of task completion (personal or pair work or group work) and the distribution of time, and also the classroom and extracurricular activities.

\section{The Application in the Classroom}

The Presentation of the Task. The presentation of the task penetrates all the classroom teaching process, before the class, during the class, and after the class. Before teaching the next lesson, the teacher could tell the learning content that will be taught to the students in order to let students do preparations purposely, and present to them in the terms of tasks. The teacher should let the students integrate the textbook content, through consulting newspapers, books, internet or even asking the experts to search for the related knowledge materials, accumulate more first-hand resources, and ensure the topic used for communication are authentical and reliable. After beginning teaching the class, the teacher should present the task from the beginning. A class can have a lot of tasks, and these tasks consist of a task cycle. The teacher proposes different tasks at different phases of the class, such as forecast tasks, order task, retelling task and so on. And the teacher presents the next task after finishing the task, and this makes students in the drive of the task all the time, so they have a strong desire for the language knowledge and technique drills, and their brains are always in an activate condition. This kind 
of learning process is a task-driven process, it is beneficial to arouse students' study interest, and help to reflect the authenticity of the task. As for those tasks that cannot be dealt with in class, the teacher could encourage students to do further discussion and research after the class.

The Preparation before the Task. As for the real life task, the teacher needs to introduce some knowledge of task contents aspect, such as a task that needs students to do introduction of the modern social family, it is necessary to tell them that there are two kinds of family (nuclear family and extended family), the former refers to the family of father, mother and kids, the latter indicates the extended family, which also includes the grandfather and grandmother, thus we can expand students' knowledge in tasks. The teacher could let students see the assembling task that others do or from other related materials, and discuss with students, and make students prepared when being questioned.

The Arrangement of the Task Practice. Compared to TBLT, the practice of the structuralism teaching is simple, the teacher is the core of the teaching, and it is easy to control the class. TBLT emphasizes the main position of students, and they become the master of their study. Thus, those students accustomed to receiving teacher's teaching may not know how to study properly, and it requires the teacher to do careful arrangement on the aspect of task practice. When the teacher arranges the task, he not only needs to propose the target and result of the task, but also tell them how to begin this learning task, how long the task will be finished, what task the students get, what kind of result they achieve after finishing the task. When the teacher arranges the task, the classroom language should be simple and brief, and the target of task study should be detailed. The pattern of task completion can be single work, or pair work, group work, or even the whole class work. And a specific pattern should depend on the actual situation. Because so many tasks are finished by pair work and group work, we should ensure the group situation before the task practice. The teacher can divide the class into seven or eight groups, and make the students that have different levels cooperate in a group and complete the task corporately. To avoid the situation that some good students are burdened with the task entirely, the group should do labor division scientifically, and let every single student realize his duty in the group, and what they need to do. The labor division should ensure that every student has a specific thing to do, and they know clearly the responsibility they burden. Thus they could experience the sense of success. In primary and middle school, normally a class has 50 students or so, even more than 50, so students could use the rule of "nearby", and choose the desk mate or neighbours to cooperate.

The Implementation. Learning tasks are required to be completed in the unit teaching or in the classroom generally, such as reading the text and answering the question, and also arranging some single long-term task, and order ing the students to finish in the given time (which cannot surpass the given time). The teacher should supervise the process of task completion, and the teacher had better divide the task into some subtasks, and let students finish in separate phases. And at every phase of task completion, students should have a time limit, therefore we can ensure that they could take it seriously, but not deal with it carelessly before the deadline. The teacher could assess the student' learning ability, learning attitude, the standard of participation, cooperation spirit by means of paperwork, oral response, lecture and intonation through the means of check, observation, and communication with students.

Language Focus. The process of task completion stresses the meaning of language; the teacher cannot interfere with students' emphasis on the language meaning. The language focus phase transmits from the language meaning to language pattern, the teacher can facilitate the student to notice the language pattern through different kinds of activities. And these activities have pertinence. The students find their shortage in language knowledge in task completion, and at the language focus phase, these shortage can be made up. The teacher analyzes and corrects the language mistakes in the process of task implementation, and strengthens students' English abilities through various patterns and the teacher can guide the students to do the two kinds of activities. a. language analysis: The students do some exercises and activities related to the language pattern in the task implementation phase, which can draw their attention of the words, sentence patterns and grammar phenomena. b. language drill: After the language analysis activity, the teacher needs to design exercises and activities to practice the words, phrases, sentence patterns in language phase, and they can fully use some patters in the traditional teaching, for example, gapped sentences, to make students write down the useful language points. Language drills 
have strong pertinence and mainly focus on the shortage in the students' task implementation, and new language phenomenon, key grammar project.

The Summary and the Assessment of the Task. The summary after the task is to make students show the task result mainly, check and assess the consequence of the task completion. The presentation of the task completion situation gives every group and single student the chance to express themselves. In the traditional teaching, the assessment of the students' learning situation is that the teacher gives answers to students after they finish the exercise. This kind of assessment pattern has a great effect on some exercise that has some standard answer. However, a majority of the students lose the chance to show themselves and this would kill the students' personality as time goes by. The task result in TBLT have no standard answer, different students have different consequence and opinion, and this cannot be assessed by means of checking the key, and it may not have the enough time to let every single student show his or her task result.

Thus, as for the task for single student, at first the students show their task result in their group, and then every group recommend their representative, who represents his group to show their task results, thus every group and every student have some chance to show their task outcome, and absorb useful components from others' result. As for the collective task that needs to be completed by the whole class, the teacher assesses the implementation situation personally. It is beneficial for the teacher to know well about the students' task completion situation, and find the existing question in the language use. As the show of the task result can draw students 'attention on the language pattern, it can improve the accuracy of students' language use.

\section{Conclusion}

The task-based language teaching method is a useful and classical teaching way to teach languages, and it can be used for reference in Chinese specific foreign language teaching environment. However, TBLT also has some advantages and disadvantages and it inspires us to do further consideration and make realistic and reasonable judgment. We can learn from the merits of TBLT and other teaching methods to offset its weakness, and let TBLT become an organical part of foreign language teaching method in our country.

\section{Acknowledgements}

This work was supported by the school project of Nanchang Normal University, named "The research into college students' English learning belief and learning strategy." (15RWYB21).

\section{References}

[1] Bailey K. M., A. Curtis \& D. Nunan. Pursuing Professional Development: The Self as Source[M]. Boston, MA : Heinle \& Heinle. 2001.

[2] Bygate, M., Skehan, P. \& Swain, M.(Eds.). Researching Pedagogic Tasks: Second Language Learning, Teaching and Testing. Oxford: Oxford University Press, 2001.

[3] Dandan Wang. Builidng the teaching mode of task-based English audio-vedio course[J]. Education exploration, 2012,(4):57-58.

[4] Ellis, R. The Study of Second Language Acquisition[M]. London: Oxford University Press. 1997.

[5] Ellis, R. Task-based Language Teaching and Learning[M]. Oxford University Press. 2003.

[6] Jingbo Zhang. The empirical study of the oral English TBLT model[J].China education journal, 2012,(6):91-92.

[7] Johnson D.W. \& Johnson R.J Learning Together and Alone: Cooperative, Competitive, and Individualistic Leaming [M]. Boston: Allyn \& Bacon, 2004 
[8] Mingming Chiu. Adapting teacher interventions to students needs during Cooperative Learning. How to improve students problem solving and time On-Task. American Education Research Journal Summer[J]. 2004, 41(2): 365-399.

[9] Nunan, D. Task-based language teaching[M]. Cambridge University Press.

[10] Penny Ur. A Course in Language Teaching:Practice and Theory [M].Cambridge:Cambridge

[11] University Press, 2000.

[12] Richards J. C. \& T. C. Farrell. Professional Development for Language Teachers[M]. New York: Cambridge University Press. 2005.

[13] Scrivener, J. Learning Teaching: a guidebook for English learning teachers. Shanghai Foreign Language Education Press, 2002

[14] Xuan He. The experimental research of the impact of TBLT on the college students' willingness of communicating in English in class [J].China adult education, 2013,(4):140-141. 